\title{
Psychometrics and Standardization of the Hindi Adaptation of the Daily Spiritual Experience Scale
}

\author{
Akbar Husain ${ }^{1 *}$, Ruchi Singh ${ }^{1}$, Shah M Khan ${ }^{2}$ and Sabira Khan ${ }^{3}$ \\ ${ }^{1}$ Department of Psychology, Aligarh Muslim University, Aligarh, India \\ ${ }^{2}$ Psychologist, Western Railway, Mumbai, India \\ ${ }^{3}$ Psychologist, Al- Karam, HBC Saproon, India
}

*Corresponding author: Akbar Husain, Department of Psychology, Aligarh Muslim University, Aligarh, India, Tel: +91 9045934355; E-mail: profakbar6@gmail.com Rec date: January 18, 2016; Acc date: March 08, 2016; Pub date: March 15, 2016

Copyright: (c) 2016 Husain A, et al. This is an open-access article distributed under the terms of the Creative Commons Attribution License, which permits unrestricted use, distribution, and reproduction in any medium, provided the original author and source are credited.

\begin{abstract}
The Hindi version of Daily Spiritual Experience Scale (DSES) was administered to 947 adults to determine the psychometric characteristics i.e. reliability, validity and norms. Cronbach's Alpha of the scale was found 0.86 . Content validity of the scale was verified by a number of experts, academicians and professionals. Good correspondence was found to exist between the scale results and the considered judgments of experienced observers. Using a more structured method, confirmatory factor analysis provided evidence of the convergent and discriminate validity. Gender norms applicable to male and female, and religion based norms applicable to Hindus and Muslims for DSES were developed using percentile ranks.
\end{abstract}

Keywords: Daily spiritual experience scale; Spirituality assessment

\section{Introduction}

The purpose of this research was to confirm as to whether the Daily Spiritual Experiences Scale (DSES) is a comprehensive and reliable scale for measuring daily spiritual experiences among Hindu and Muslim religious devotees in India. This scale is designed to help researchers and practitioners in assessing the current state of Daily Spiritual Experiences (DSE). The Daily Spiritual Experiences Scale (DSES) is a uni-dimensional scale. This scale was designed to assess ordinary experiences of connection with the transcendent in daily life. It includes constructs such as awe, gratitude, mercy, sense of connection with the transcendent and compassionate love. It also includes measures of awareness of discernment/inspiration and a sense of deep inner peace.

One of the qualities of religious/spiritual people is to have some sacred or spiritual/religious experiences. Spiritual/religious experiences are the subjective feeling of the spiritual/religious person in whom he experiences that he is being connected to all of the other living beings in this universe, created by the universal power, and also connected to that universal power which is transcendental in nature. Such an experience often involves arriving at some insight or knowledge that is previously unavailable to the person. Religious experience generally brings understanding, complete or partial, of issues of a fundamental character that may have been a cause (whether consciously acknowledged or not) of alienation or anguish to the person for an extended period of time. This may be experienced as a form of healing, enlightenment or conversion. Having these spiritual/religious experiences people gradually makes progress on the path of spiritual development.

\section{Concept and definitions of spiritual experience}

William James (1902/1958) used the term "religious experience" in his book entitled "The Varieties of Religious Experience" [1]. A religious experience (sometimes known as a spiritual experience, sacred experience, or mystical experience) is a subjective experience which is interpreted within a religious framework [2].

Religious experiences are classified into two classes.

\section{Mediated}

In the mediated religious experience, the believer experiences the sacred through the mediators such as special persons, rituals, religious groups, the natural world or the totemic objects [3].

\section{Immediate}

In the immediate religious experience the believer experiences the sacred without any intervening mediator or agency. The divine or deity is experienced directly.

Underwood and Teresi, define spiritual experiences as, "the perception of the transcendent and the perception of interaction with, or involvement of the transcendent in life" [4]. Hinterkopf defines "spirituality or spiritual experience (is) a subtle, bodily feeling with vague meanings that brings new, clearer meaning involving a transcendent growth process" [5].

The Spiritual Science Research Foundation [6] defines 'experience' which is experienced through the medium of the five senses, intellect and mind. For example, the experience of eating one's favorite dish, resolving a problem at work by using one's intellect and feeling of love for one's child etc., fall into the category of an 'experience'. Experiencing something which is beyond the comprehension of the five senses, intellect and mind fall into the category of 'spiritual experience. Even if one can perceive an event through the five senses, 
intellect and mind but the reason behind it is beyond the gross intellect of mankind, it still composes a spiritual experience.

We experience the whole world through the five senses, intellect and mind. Corresponding to the five senses, intellect and mind that we are well aware of, we have five subtle senses also, a subtle intellect and subtle mind and, which when activated or developed, help us to experience the subtle world. This experience of the subtle world is known as a 'spiritual experience.' The SSRF defines the 'subtle world' as the world which is beyond the understanding of the five senses, intellect and mind. The subtle world refers to the unseen world of angels, heaven etc which can only be perceived through our sixth sense.

According to SSRF, the intellectual or theoretical knowledge in worlds has only $2 \%$ importance whereas $98 \%$ importance lies in experiencing those worlds. When one undertakes an appropriate spiritual practice on the basis of the basic principles of spiritual science then he/she makes spiritual progress and gets spiritual experiences. Spiritual practices bridge the gap between intellectual or theoretical knowledge (which are obtained from the books) and spiritual experiences. The reason for this is that spiritual experiences are mostly discussed during the spiritual meetings. Seekers, who attend the spiritual meetings, realize that what is taught there in terms of spiritual knowledge is not mere information but that it can be actually experienced. Theoretical knowledge only assists those curious about the spiritual science in gaining some belief. It is a very necessary step in the stages of one's spiritual development, however, when one gets spiritual experiences, develops faith in the theoretical knowledge also.

Spiritual experiences are the indicators of one's spiritual progress. However, spiritual progress may not begin as soon as one begins appropriate spiritual practice. The reason behind this is that spiritual practices may be used, instead of solely for spiritual progress, to reduce the intensity of severe negative destiny. As a result, initially spiritual progress does not occur and hence one does not get spiritual experiences. However spiritual practices enable us to overcome this initial phase [6].

William [1] considers the following four characteristics of religious/ mystical experience which he explains in The Varieties of Religious Experience.

\section{Transient}

The experience is temporary; the individual soon returns to a "normal" frame of mind. It is outside our normal perception of space and time.

\section{Ineffable}

The experience cannot be adequately put into words.

\section{Noetic}

The individual feels that he or she has learned something valuable from the experience. It gives us knowledge that is normally hidden from human understanding.

\section{Passive}

The experience happens to the individual, largely without conscious control. Although there are activities, such as meditation, that can make religious experience more likely, it is not something that can be turned on and off at will.

\section{Materials and Method}

\section{Participants}

Participants for the study were 947 religious devotees. Of these, 597 were Hindus (471 Male and179 Female) and 350 were Muslims (179 Male \& 171 Female). Hindus were randomly selected from the MahaKumbh Mela- 2013 (a great religious gathering for Hindus) held in Allahabad and Muslims were randomly selected from different mosques situated in Aligarh district of U.P. Sixty-three percent devotees were Hindus (597) and thirty-seven percent devotees were Muslims (350). Their age varied from 21 to 60 with mean age 35.40 years.

\section{Description and adaptation of the scale}

The Daily Spiritual Experiences Scale (DSES) was originally developed by [4]. Details on the English version were published in some articles [7-12]. Hindi translation of the DSES was done in 2012 by Vibhuti Gupta and Lynn Underwood. Hindi version of DSES was used in this research to determine the psychometric properties In Hindu and Muslim devotees. It is a uni-dimensional scale. The DSES is a 16-item self-report scale along a 6-point Likert scale (item 1 to 15) anchors labeled; Many times in a day, Every day, Most days, Some days, once in a while and Never and 4 point- Likert scale (item 16) labeled Not at all, Somewhat close, Very close and As close as possible. The DSES is highly reliable (internally consistent) with Cronbach's alpha ranging from 94 to 95 with GSS.

\section{First draft and item analysis}

To determine the psychometric properties of the scale, this scale was administered on a representative sample of 947 (597 Hindus and 350 Muslim) religious devotees. After scoring the scale of each examinee, the sheets were arranged in the order of highest scoring to lowest scoring. From this order, two groups, one of $27 \%$ from highest scoring and other of $27 \%$ from the lowest scoring were selected. In these two groups inter-correlation matrix was examined in order to overcome existence of multi-co-linearity (i.e. items that are highly correlated) and singularity (i.e. items that are perfectly correlated) in the scale.

\begin{tabular}{|l|l|l|l|}
\hline No. & Dimensions & No. of Items & $\begin{array}{l}\text { Total No. of } \\
\text { items }\end{array}$ \\
\hline 1 & Spiritual Daily Experience & $1-15$ & 15 \\
\hline DSES Total & $1-15$ & 15 \\
\hline
\end{tabular}

Table 1: Daily spiritual experience dimension and number of items.

In addition to inter-correlation matrix, 'Determinant' of the Rmatrix was estimated and it was greater than 0.00001. Sampling adequacy was also carried out and found to be greater than 0.50 . On this basis item No. 16th was rejected and the final draft of the scale had 15 items. In order to confirm the dimensionality, Confirmatory Factor Analysis (CFA) was carried out and results are shown in following tables. The description of dimension is given in Table 1. 
Citation: Husain A, Singh R, Khan SM, Khan S (2016) Psychometrics and Standardization of the Hindi Adaptation of the Daily Spiritual

Page 3 of 6

\begin{tabular}{|c|c|c|c|c|c|}
\hline $\begin{array}{l}\text { Many } \\
\text { times a } \\
\text { day }\end{array}$ & Every day & Most days & $\begin{array}{l}\text { Some } \\
\text { Days }\end{array}$ & $\begin{array}{l}\text { Once in a } \\
\text { while }\end{array}$ & Never \\
\hline 6 & 5 & 4 & 3 & 2 & 1 \\
\hline
\end{tabular}

Table 2: Showing scoring system.

The test sheets were scored as per scoring criterion given in Table 2. The responses of all 15 items were added to generate overall DSES score. Thus, the minimum possible score for DSES will be 15 and the maximum 90. Higher the score indicates high daily spiritual experiences and lower the score indicates low daily spiritual experiences.

\begin{tabular}{|c|c|c|c|c|c|c|c|c|}
\hline \multirow{2}{*}{$\begin{array}{l}\text { Item } \\
\text { No. }\end{array}$} & \multicolumn{4}{|c|}{ Descriptive Statistics for Items } & \multicolumn{4}{|c|}{ Descriptive Statistics for Scale } \\
\hline & Range & Mean & Median & SD & $\begin{array}{l}\text { Scale Mean if item } \\
\text { deleted }\end{array}$ & $\begin{array}{l}\text { Scale Variance if item } \\
\text { deleted }\end{array}$ & $\begin{array}{l}\text { *Item } \\
\text { correlation }\end{array}$ & $\begin{array}{l}\text { Alpha if item } \\
\text { deleted }\end{array}$ \\
\hline DSe1 & $1-6$ & 5.24 & 5 & 0.977 & 65.17 & 107.403 & 0.52 & 0.85 \\
\hline DSe2 & $1-6$ & 4.61 & 5 & 1.354 & 65.8 & 104.851 & 0.44 & 0.854 \\
\hline DSe3 & $1-6$ & 5.05 & 5 & 1.012 & 65.36 & 106.459 & 0.546 & 0.849 \\
\hline DSe4 & $1-6$ & 5.03 & 5 & 0.98 & 65.38 & 105.792 & 0.601 & 0.847 \\
\hline DSe5 & $1-6$ & 4.99 & 5 & 1.041 & 65.42 & 105.462 & 0.577 & 0.847 \\
\hline DSe6 & $1-6$ & 4.8 & 5 & 1.177 & 65.62 & 103.862 & 0.568 & 0.847 \\
\hline DSe7 & $1-6$ & 4.91 & 5 & 1.33 & 65.5 & 106.411 & 0.39 & 0.856 \\
\hline DSe8 & $1-6$ & 4.87 & 5 & 1.113 & 65.54 & 104.94 & 0.557 & 0.848 \\
\hline DSe9 & $1-6$ & 4.59 & 5 & 1.304 & 65.82 & 100.301 & 0.646 & 0.842 \\
\hline DSe10 & $1-6$ & 4.42 & 5 & 1.398 & 65.99 & 99.883 & 0.61 & 0.844 \\
\hline DSe11 & $1-6$ & 4.37 & 5 & 1.376 & 66.04 & 100.903 & 0.582 & 0.845 \\
\hline DSe12 & $1-6$ & 4.89 & 5 & 1.206 & 65.52 & 105.801 & 0.469 & 0.852 \\
\hline DSe13 & $1-6$ & 4.44 & 5 & 1.336 & 65.97 & 104.574 & 0.458 & 0.852 \\
\hline DSe14 & $1-6$ & 3.54 & 4 & 1.607 & 66.88 & 106.9 & 0.283 & 0.865 \\
\hline DSe15 & $1-6$ & 4.66 & 5 & 1.402 & 65.76 & 105.443 & 0.398 & 0.856 \\
\hline
\end{tabular}

Table 3a: Showing descriptive statistics of items, Scale Alpha. ${ }^{*} \mathrm{r}=.05(\mathrm{p}<.05) ; .08(\mathrm{p}<.01)$.

\begin{tabular}{|c|c|c|c|c|c|c|c|c|}
\hline \multirow{3}{*}{$\begin{array}{l}\text { Statistics for } \\
\text { Scale }\end{array}$} & \multicolumn{5}{|c|}{ Scale Statistics } & \multicolumn{2}{|c|}{ Alpha Coefficient } & \multirow[t]{2}{*}{ No. of Items } \\
\hline & Mean & Median & Mode & Variance & SD & Raw Items & Standardized items & \\
\hline & 70.41 & 71 & 70.9 & 118.88 & 10.9 & 0.86 & 0.87 & 15 \\
\hline
\end{tabular}

Table 3b: Descriptive statistics of scale and reliability (Cronbach's' Alpha).

The Cronbach's Alpha of the scale was found 0.86. The internal consistency of the scale is quite high and this gives a support that the scale is highly reliable.

\section{Validity}

Content validity of the scale was verified by number of experts, academicians and professionals. Good correspondence was found to

\section{Results}

\section{Reliability}

The considerations of validity and reliability typically are viewed as essential elements for determining the quality of any standardized test. For establishing the internal consistency reliability, Cronbach's alpha is used and shown along with other descriptive statistics in Table $3 \mathrm{a}$ and $3 b$. 
Citation: Husain A, Singh R, Khan SM, Khan S (2016) Psychometrics and Standardization of the Hindi Adaptation of the Daily Spiritual Experience Scale. Clin Exp Psychol 2: 117. doi:10.4172/2471-2701.1000117

Page 4 of 6

singularity 'Determinant' of the R-matrix was estimated and it was 0.007 which is greater than 0.00001 . Kaiser-Meyer-Olkin Measure of Sampling Adequacy was also estimated and found to be greater than 0.50 as required in both cases. The percent of variance accounted by the uni-factor explained $59.81 \%$ of the total variance. The construct validity of the scale is highly satisfactory.

\begin{tabular}{|l|l|l|l|l|}
\hline Item & \multicolumn{4}{|c|}{ Model Estimates } \\
\hline & Parameter & Standard & $\mathbf{t}^{*}$ & Prob. \\
\hline (Dim1)-1->[dsse1] & 0.573 & 0.03 & 18.794 & 0.001 \\
\hline (Dim1)-2->[dses2] & 0.668 & 0.044 & 15.3 & 0.001 \\
\hline (Dim1)-3->[dses3] & 0.611 & 0.031 & 19.489 & 0.001 \\
\hline (Dim1)-4->[dses4] & 0.682 & 0.029 & 23.363 & 0.001 \\
\hline (Dim1)-5->[dses5] & 0.688 & 0.032 & 21.817 & 0.001 \\
\hline (Dim1)-6->[dses6] & 0.755 & 0.036 & 21.02 & 0.001 \\
\hline (Dim1)-7->[dses7] & 0.563 & 0.044 & 12.879 & 0.001 \\
\hline (Dim1)-8->[dses8] & 0.674 & 0.035 & 19.518 & 0.001 \\
\hline (Dim1)-9->[dses9] & 0.92 & 0.039 & 23.79 & 0.001 \\
\hline (Dim1)-10->[dses10] & 0.922 & 0.042 & 21.762 & 0.001 \\
\hline (Dim1)-11->[dses11] & 0.843 & 0.043 & 19.819 & 0.001 \\
\hline (Dim1)-12->[dses12] & 0.561 & 0.039 & 14.323 & 0.001 \\
\hline (Dim1)-13->[dses13] & 0.589 & 0.044 & 13.479 & 0.001 \\
\hline (Dim1)-14->[dses14] & 0.422 & 0.054 & 7.751 & 0.001 \\
\hline (Dim1)-15->[dses15] & 0.563 & 0.046 & 12.166 & 0.001 \\
\hline
\end{tabular}

Table 4: Showing model estimates for DSES. ${ }^{*} \mathrm{t}=3.098(\mathrm{p}<0.001)$.

Using a more structured method, confirmatory factor analysis provides evidence of the convergent and discriminant validity. The model summary for confirming the emergence of each item in the uni- dimension estimated through Confirmatory Factor Analysis (CFA) and is given in Table 4.

The parameter estimates for each item is highly significant as probability to reject the hypothesis was $(\mathrm{p}<0.001)$ level of significance. The summary statistics of Confirmatory Factor Analysis (CFA) for the scale is given in Table 5 .

\begin{tabular}{|l|l|}
\hline Parameters & Values \\
\hline Discrepancy Function & 1.099 \\
\hline Maximum Residual Cosine & 0 \\
\hline Maximum Absolute Gradient & 0 \\
\hline ICSF Criterion & 0 \\
\hline ICS Criterion & 0 \\
\hline ML Chi-Square & 1039.725 \\
\hline Degrees of Freedom & 90 \\
\hline p-level & 0 \\
\hline RMS Standardized Residual & 0.068 \\
\hline
\end{tabular}

Table 5: Showing basic summary statistics.

Maximum Likelihood Chi-square is highly significant as $\mathrm{p}$ value is less than 0.001 , this substantiate that all 15 items of the scale are measuring single construct and it can be concluded that this scale is uni-dimensional and may be labelled as "Daily Spiritual Experience".

\section{Norms}

Gender norms applicable to male and female, and religion based norms applicable to Hindus and Muslims for DSES were developed using percentile ranks and are shown in Tables 6. A percentile (or a centile) is a measure used in statistics indicating the value below which a given percentage of observations in a group of observations fall. The term percentile and the related term percentile rank are often used in the reporting of scores from norm-referenced tests.

\begin{tabular}{|c|c|c|c|c|c|c|c|c|c|c|}
\hline \multirow{3}{*}{ Stanine } & \multirow{3}{*}{$\begin{array}{l}\text { Percentile } \\
\text { Ranking } \\
\text { (Range) }\end{array}$} & \multicolumn{9}{|c|}{ Raw Score (DSE) } \\
\hline & & \multicolumn{3}{|c|}{ Hindu } & \multicolumn{3}{|c|}{ Muslim } & \multicolumn{3}{|c|}{ Overall } \\
\hline & & Male & Female & Overall & Male & Female & Overall & Male & Female & Overall \\
\hline 1 & 1 to 4 & $\leq 48.00$ & $\leq 49.20$ & $\leq 48.92$ & $\leq 47.60$ & $\leq 55.76$ & $\leq 52.00$ & $\leq 48.00$ & $\leq 53.04$ & $\leq 50.92$ \\
\hline 2 & 5 to 11 & $\begin{array}{l}48.01 \\
57.09\end{array}$ & $49.21-57.0$ & $48.93-57.0$ & $\begin{array}{l}47.61 \\
55.8\end{array}$ & $55.77-60.0$ & $52.01-58.0$ & $\begin{array}{l}48.01- \\
57.0\end{array}$ & $53.05-59.0$ & $50.93-58.0$ \\
\hline 3 & 12 to 23 & $57.10-64.0$ & $57.01-61.0$ & $57.01-63.0$ & $\begin{array}{l}55.81 \\
61.0\end{array}$ & $60.01-65.0$ & $58.01-63.0$ & $\begin{array}{l}57.01 \quad- \\
63.0\end{array}$ & $59.01-63.0$ & $58.01-63.0$ \\
\hline 4 & 24 to 40 & $64.01-69.0$ & $61.01-66.0$ & $63.01-68.0$ & $\begin{array}{l}61.01 \quad- \\
66.0\end{array}$ & $65.01-70.0$ & $63.01-68.0$ & $\begin{array}{l}63.01 \quad- \\
68.0\end{array}$ & $63.01-68.0$ & $63.01-68.0$ \\
\hline 5 & 41 to 60 & $69.01-74.0$ & $66.01-70.0$ & $68.01-73.0$ & $\begin{array}{l}66.01 \\
73.0\end{array}$ & $70.01-76.0$ & $68.01-74.0$ & $\begin{array}{l}68.01 \quad- \\
74.0\end{array}$ & $68.01-73.0$ & $68.01-73.0$ \\
\hline 6 & 61 to 77 & $74.01-88.0$ & $70.01-77.0$ & $73.01-79.0$ & $\begin{array}{l}73.01 \\
78.0\end{array}$ & $76.01-81.0$ & $74.01-79.0$ & $\begin{array}{l}74.01 \quad- \\
79.0\end{array}$ & $73.01-79.0$ & $73.01-79.0$ \\
\hline
\end{tabular}


Citation: Husain A, Singh R, Khan SM, Khan S (2016) Psychometrics and Standardization of the Hindi Adaptation of the Daily Spiritual Experience Scale. Clin Exp Psychol 2: 117. doi:10.4172/2471-2701.1000117

Page 5 of 6

\begin{tabular}{|l|l|l|l|l|l|l|l|l|l|l|l|}
\hline 7 & 78 to 89 & $88.01-85.0$ & $77.01-83.0$ & $79.01-84.0$ & $\begin{array}{l}78.01 \\
82.0\end{array}$ & $-81.01-85.0$ & $79.01-84.0$ & $\begin{array}{l}79.01 \\
84.0\end{array}$ & - & $79.01-84.0$ & $79.01-84.0$ \\
\hline 8 & 90 to 96 & $85.01-90.0$ & $83.01-90.0$ & $84.01-90.0$ & $\begin{array}{l}82.01 \\
88.0\end{array}$ & $-85.01-88.0$ & $84.01-88.0$ & $\begin{array}{l}84.01 \\
90.0\end{array}$ & $84.01-88.0$ & $84.01-90.0$ \\
\hline 9 & 97 to 100 & $\geq 90.01$ & $\geq 90.01$ & $\geq 90.01$ & $\geq 88.01$ & $\geq 88.01$ & $\geq 88.01$ & $\geq 90.01$ & $\geq 88.01$ & $\geq 90.01$ \\
\hline
\end{tabular}

Table 6: Showing religion, gender-wise and overall norms for daily spiritual experiences.

The interpretation of norms as given in Table 6 can be made using the Table 7 and is valid for male and female Hindu as well as Muslim devotees.

\begin{tabular}{|l|l|l|l|}
\hline Stanine & $\begin{array}{c}\text { Percentile } \\
\text { Ranking } \\
\text { (Range) }\end{array}$ & \multicolumn{1}{|c|}{ Grade } & \multicolumn{1}{|c|}{ Level of DSE } \\
\hline 1 & 1 to 4 & I & Extremely Low (Negative) \\
\hline 2 & 5 to 11 & H & Slightly Low (Negative) \\
\hline 3 & 12 to 23 & G & Moderately Low (Negative) \\
\hline 4 & 24 to 40 & F & Low (Negative) \\
\hline 5 & 41 to 60 & E & Average/Moderate (Neutral) \\
\hline 6 & 61 to 77 & D & High (Positive) \\
\hline 7 & 78 to 89 & C & Slightly High (Positive) \\
\hline 8 & 90 to 96 & B & Moderately High (Positive) \\
\hline 9 & 97 to 100 & A & Extremely High (Positive) \\
\hline
\end{tabular}

Table 7: Showing norms interpretation of the daily spiritual experience (dse).

\begin{tabular}{|c|c|c|c|c|c|c|c|c|c|}
\hline \multirow[b]{3}{*}{ Religion } & \multicolumn{9}{|c|}{ Gender } \\
\hline & \multicolumn{3}{|c|}{ Male } & \multicolumn{3}{|c|}{ Female } & \multicolumn{3}{|c|}{ Overall } \\
\hline & Mean & SD & $\mathbf{N}$ & Mean & SD & $\mathbf{N}$ & Mean & SD & $\mathbf{N}$ \\
\hline Hindu & 70.9 & 11.24 & 418 & 68.8 & 10.56 & 179 & 70.27 & 11.07 & 597 \\
\hline Muslim & 68.84 & 11.19 & 179 & 72.54 & 9.67 & 171 & 70.65 & 10.62 & 350 \\
\hline Overall & 70.28 & 11.25 & 597 & 70.63 & 10.29 & 350 & 70.41 & 10.9 & 947 \\
\hline
\end{tabular}

Table 8: Showing descriptive statistics for DSES gender and religion wise.

\section{Conclusions}

1. Reliability, validity and stability data based on 947 religious devotees revealed that DSES has quite satisfactory psychometric characteristics. It can be concluded that the DSES is highly reliable and valid to measure the daily spiritual experiences among the followers of Hindu and Muslim religions.

2. The confirmatory factor analysis provided evidence of the convergent and discriminant validity.

3. The construct validity of the DSES is highly satisfactory.

4. The findings of the present study showed that the Hindi version of DSES can be used for research purposes.
For example, if a male examinee secured a score of 64 and in Table 6 this score belongs between 24th to 40th percentile ranks which can be labelled as "Low Negative" DSEs. Similarly, other norms viz. Normalized T-score, Z-score, etc. can be developed using the Table 8 and interpretation about daily spiritual experiences gender and religion wise may be made.

\section{Discussion}

The objective of the survey was to determine the psychometric characteristics, i.e. reliability, validity, and norms; and confirmatory factor analysis of the DSES among Indian population (Hindus and Muslims). The analysis of the internal consistency and item correlations demonstrated the adequate reliability of the DSES. Using a more structured method, confirmatory factor analysis provided evidence of the convergent and discriminant validity. For the practical use of the DSES, gender norms applicable to male and female, and religion based norms applicable to Hindus and Muslims were developed using percentile ranks.

\section{Acknowledgement}

We acknowledge the cooperation and support extended by the developer of the DSES, Dr. Lynn Underwood, President, Research Integration, lynnunderwood@researchintergation.org Honorary Fellow, University of Liverpool, UK for giving permission to us to standardize the Hindi version of the Daily Spiritual Experience Scale on the Indian population. Permission to copy and use the scale is required from Dr. Underwood.

\section{References}

1. James W (2014) Religious experience.

2. Samy AM, Vander ST (1998) Waaromkwambodhidharmanaar het westen? De ontmoeting van zen met het westen, Asoka: Asoka. 
Citation: Husain A, Singh R, Khan SM, Khan S (2016) Psychometrics and Standardization of the Hindi Adaptation of the Daily Spiritual Experience Scale. Clin Exp Psychol 2: 117. doi:10.4172/2471-2701.1000117

Page 6 of 6

3. Habel N, Donoghue O, Michael, Maddox M (1993) 'Religious experience' In: Myth, ritual and the sacred. Introducing the phenomena of religion (Underdale: University of South Australia).

4. Underwood LG, Teresi JA (2002) The daily spiritual experience scale: Development, theoretical description, reliability, exploratory factor analysis, and preliminary construct validity using health related data. Ann Behav Med 24: 22-33.

5. Hinterkopf E (1998) Integrating spirituality in counselling: A manual for using the experiential focusing method (1stedn), Jessica Kingsley publishers, London, United Kingdom.

6. Spiritual Science Research Foundation (2013) What is spiritual experience?

7. Hori VS (1994) Teaching and learning in the zen rinzai monastery. J Jpn Stud 20: 5-35.
8. Sharf RH (2000) The rhetoric of experience and the study of religion. J Consciousness Stud 7: 267-87.

9. Moore B, Habel N (1982) In: When religion goes to school (Adelaide: SACAE). 184-218.

10. Underwood LG (1999) Multidimensional measurement of religiousness/ spirituality for use in health research: a report of the fetzer institute/ national institute on aging working group.

11. Underwood LG (2006) Ordinary spiritual experience: Qualitative research, interpretive guidelines, and population distribution for the Daily Spiritual Experience Scale. Arch Psychol Relig 28: 181-218.

12. Underwood LG (2011) The daily spiritual experience scale: overview and results. Religions 2: 29-50. 